\title{
On the Development of a Simple and Robust Active Control System for Boring Bar Vibration in Industry
}

\author{
Henrik Åkesson, Tatiana Smirnova, Ingvar Claesson and Lars Håkansson ${ }^{\dagger}$ \\ Department of Signal Processing, Blekinge University of Technology, 37225 Ronneby, Sweden
}

(Received 4 May 2007; accepted 24 September 2007)

\begin{abstract}
Vibration in internal turning is a problem in the manufacturing industry. A digital adaptive controller for the active control of boring bar vibration may not be a sufficient solution to the problem. The inherent delay in a digital adaptive controller delays control authority and may result in tool failure when the load applied by the workpiece on the tool changes abruptly, e.g. in the engagement phase of the cutting edge. A robust analog controller, based on a lead-lag compensator, with simple adjustable gain and phase, suitable for the industry application, has been developed. Also, the basic principle of an active boring bar with embedded actuator is addressed. The performance and robustness of the developed controller has been investigated and compared with an adaptive digital controller based on the feedback filtered-x algorithm. In addition, this paper takes into account those variations in boring bar dynamics which are likely to occur in industry; for example, when the boring bars is clamped in a lathe. Both the analog and the digital controller manage to reduce the boring bar vibration level by up to approximately $50 \mathrm{~dB}$.
\end{abstract}

${ }^{\dagger}$ Member of the International Institute of Acoustics and Vibration (IIAV)

\section{INTRODUCTION}

Degrading vibrations in metal cutting e.g. turning, milling, boring and grinding are a common problem in the manufacturing industry. In particular, vibration in internal turning operations is a pronounced problem. To obtain the required tolerances of the workpiece shape, and adequate tool-life, the influence of vibration in the process of machining a workpiece must be kept to a minimum. This requires that extra care be taken in production planning and preparation. Vibration problems in internal turning have a considerable influence on important factors such as productivity, production costs, working environment, etc. In internal turning the dimensions of the workpiece hole will generally determine the length and limit the diameter or cross-sectional size of the boring bar. As a result, boring bars are frequently long and slender - long-overhang cantilever tooling- and thus sensitive to excitation forces introduced by the material deformation process in the turning operation. ${ }^{1-3}$ The vibrations of a boring bar are often directly related to its low-order bending modes. ${ }^{4-6}$

The vibration problems in internal turning can be addressed using both passive and active methods. ${ }^{1,2,7}$ Common methods used to increase dynamic stiffness of cantilever tooling involve making them (in high Young's modulus) nonductile materials, such as sintered tungsten carbide and machineable sintered tungsten, and/or utilising passive Tuned Vibration Absorbers (TVA)., ${ }^{1,2}$ These passive methods are known to enhance the dynamic stiffness and stability (chatter-resistance) of long cutting tools and thus, enable the allowable overhang to be increased., ${ }^{1,2,8}$ The passive methods offer solutions with a fix enhancement of the dynamic stiffness frequently tuned for a narrow frequency range comprising a certain bending mode frequency that in some cases may be manually adjusted. ${ }^{1,2,8}$ On the other hand, the active control of tool vibration enables a flexible solution that selectively increases the dynamic stiffness at the actual frequency of the dominating bending modes until the level of the chatter component in the feedback signal is negligible., ${ }^{2,79}$ An active control approach was reported by Tewani et al. ${ }^{10,11}$ concerning active dynamic absorbers in boring bars controlled by a digital state feedback controller. It was claimed to provide a substantial improvement in the stability of the cutting process. Browning et al. ${ }^{12}$ reported an active clamp for boring bars controlled by a feedback version of the filtered-x LMS algorithm. They assert that the method enables to extend the operable length of boring bars. Claesson and Håkansson" controlled tool vibration by using the feedback filtered-x LMS algorithm to control tool shank vibration in the cutting speed direction without applying the traditional regenerative chatter theory.

Two important constraints concerning the active control of tool vibration involve the difficult environment in a lathe and industry demands. It is necessary to protect the actuator and sensors from the metal chips and cutting fluid. Also, the active control system should be applicable to a general lathe. Pettersson et al. ${ }^{13}$ reported an adaptive active feedback control system based on a tool holder shank with embedded actuators and vibration sensors. This control strategy was later applied to boring bars by Pettersson et al. ${ }^{6}$ Åkesson et al. ${ }^{14}$ reported successful application of active adaptive control of boring bar vibration in industry using an active boring bar with embedded actuators and vibration sensors.

During the process of machining a workpiece in a lathe, the boundary conditions applied by the workpiece on the cutting tool may exhibit large and abrupt variation, particularly in the engagement phase between the cutting tool and workpiece. These abrupt changes of load applied by the workpiece on the tool may result in tool failure. However when utilising 